\title{
Working Hour, Work-Life Balance and Mental Health on Construction Workers
}

\author{
Fanny Y. F. Young \\ Department of Business Administration, Hong Kong Shue Yan University, Hong Kong SAR, China
}

Email address:

drfyoung@gmail.com

\section{To cite this article:}

Fanny Y. F. Young. Working Hour, Work-Life Balance and Mental Health on Construction Workers. Journal of Human Resource Management. Vol. 4, No. 5, 2016, pp. 49-54. doi: 10.11648/j.jhrm.20160405.11

Received: August 21, 2016; Accepted: September 1, 2016; Published: September 21, 2016

\begin{abstract}
This study investigated the working hours, work-life balance and mental health of 100 construction workers in a place without Standard Working Hour legislation, Hong Kong, using a questionnaire survey. Results showed these participants had longer working hours (54 hours/week) than many other workers in Hong Kong and in many other places. However, the results did not show the work-life balance was as poor as another long working hour industry in Hong Kong, public doctors. The mental health condition (mean GHQ score 9.66) was not shown to be poor. There existed some associations among long working hours, poor work-life balance and poor mental health condition. To conclude, construction workers in Hong Kong, without Standard Working Hour legislation, had long working hours but there was insufficient evidence to show they have poor work-life balance and poor mental health. There was insufficient evidence to show the high risk of occupational injuries was related to poor work-life balance and poor mental health.
\end{abstract}

Keywords: Mental Health, Construction Workers, Standard Working Hour, Working Hours, Work-Life Balance

\section{Introduction}

There exists some evidence of a relation between long working hours and an increased risk of occupational injuries among construction workers [1]. Long working hours indirectly precipitate workplace accidents by inducing fatigue or stress in affected workers [2]. Long working hours result in a poor work-life balance, with ill effects such as an unwilling to work, a great likelihood of changing jobs, disharmony, lack of exercise, stress, poor diet, exhaustion, insomnia, depression and health problems (e.g., cancer) [3]. Work-life balance describes an individual's control over their work. A balance is achieved when an individual's right to a fulfilled life inside and outside paid work is accepted and respected as the norm, to the mutual benefit of the individual, business and society [4].

Several cross-sectional studies have shown an association between long working hours and mental ill health and fatigue symptoms [5].

Mental health problems in the workplace are highly prevalent and burdensome. Treatment costs and the indirect costs of lost productivity represent a substantial economic liability [6].

Long working hour can be a more severe problem in places with no legislation, and it can be much more serious in densely populated metropolitan cities. Hong Kong has no legislation performed on Standard Working Hours [7]. Hong Kong full-time employees worked on average 49 hours per week, which was much higher than the maximum 40 hour work week defined by law in many countries $[7,8]$.

In Hong Kong, construction industry is one of the industries with longest working hours [8]. In addition, construction workers frequently need to perform heavy physical activities which may be more prone to have physical and mental stress. It also recorded the highest number of fatalities and accident rate among all industries, in particular when the construction workers were under work pressure to meet tight project deadlines [9]. This problem is aggravated by the manpower shortage of construction workers in Hong Kong [10]. The number of fatal and non-fatal industrial accidents in construction workers had been remaining high since 2011, a total number of 36 industrial fatalities in construction works was recorded in the past four years from 2011 to 2014 [9].

Little is generally known about the effect of long working 
hours on mental health [11] and no large-scale epidemiological study has assessed the current level of mental health needs in Hong Kong [12]. In fact, very few studies have investigated the relationship between working hours, work-life balance and mental health conditions of construction workers of any place.

Therefore, it is important to explore the severity and effect of long working hours in full-time construction workers, especially in relation to work-life balance and mental health and to see whether the high risk of occupational injuries was related to poor work-life balance and poor mental health.

Research Aim: to investigate the working hours, work-life balance and mental health of full-time construction workers in Hong Kong.

\section{Material and Methods}

The study was performed using a questionnaire survey. People employed as full-time construction workers in different locations in Hong Kong were randomly selected and invited to answer the questionnaire in a voluntary and anonymous basis. No personal identifiers were collected.

The questionnaire was a combination of the modified questionnaire used to study the work-life balance of the general Hong Kong population [8] which assessed working hours and work-life balance conditions, and the modified 12item General Health Questionnaire (GHQ) [13] which assessed mental health condition. GHQ was originally developed by Goldberg and it has been widely used as a screening tool for individual risk of developing a psychiatric disorder [13]. It has been used extensively by researchers and has been found to be reliable and well-validated [14]. The GHQ score was used to generate a total score by summation ranging from 0 to 36 . A high GHQ score indicated poor mental health [15].

The following areas are included in the questionnaire: working hour condition (item 1); hours spent on personal or private activities (item 2); self-perception of work-life balance condition (item 3); problem encountered because of disturbed work-life balance (Productivity and work quality has reduced dramatically due to long working hours, Prolonged fatigue level, sleepiness and extreme tiredness, I get physically sick easily and frequently due to heavy workload, I do not have any private time for recreation activities or sports at all, My work has affected my relationship with my friends, I don't have time staying with my partner and family, I feel stressed out, depressed and exhausted after work, Work pressure creates insomnia and poor diet, I become accident-prone, I do not want to get married, I do not want to have children and Others, item 4); problems related to mental health condition (the conditions experienced in the past few weeks: Generally feeling unhappy, Thinking of self as worthless, Losing confidence, Feeling unhappy and depressed, Could not overcome difficulties, Incapable making decision, Cannot face up problems, Unable to concentrate, Do not enjoy normal activities, Do not play useful role in things, Constantly under strain, and Lost much sleep, item 5); arrangements for improvement of the work-life balance condition (Flexible working time, 5-day work week, Paternity leave, Longer maternity leave, Option to work from home sometimes, Free sports facilities, Crèche facilities/Child care, Work support services, Job-share, Career breaks, and More paid annual leave, item 6); arrangements that may improve stressful working condition (Reduce Working Hours, Hiring More Staff, Reduce Workload, and to Improve Relationship between Subordinates and Supervisors. item 7); gender (item 8); age (item 9); education attainment (item 10) and job experience in construction (item 11).

Participants were asked individually face to face on each item and the responses were recorded on the questionnaire sheet in front of the participants.

Sample size determination: It was targeted to obtain a sample size of 100 participants which was comparable to that of similar studies [16].

The data were entered to an Excel (Microsoft Office v.2010, U.S.A.) file for further data analyses. Correlation analyses were performed between working hours and worklife balance; working hours and mental health condition and work-life balance and mental health condition using Instat (v.3, U.S.A.).

The working hour was assessed using item 1. The worklife balance was assessed using item 3 . The mental health condition was assessed using GHQ score, which was the summation of response scores of the modified GHQ, item 5 [15].

\section{Results}

100 questionnaires were completed and the data were analysed and presented below:

\subsection{Demographic Data}

The male to female ratio of the subjects was around 96:4. They in general belonged to the middle age groups, with 63 per cent in the $40-49$ groups; few were within the young age groups, with 11 per cent in the $20-29$ groups and 10 per cent in the $30-39$ groups (Table-1).

Table 1. Age distribution.

\begin{tabular}{ll}
\hline Age range & Number $(\%)$ \\
\hline $20-24$ & $4(4 \%)$ \\
$25-29$ & $7(7 \%)$ \\
$30-34$ & $4(4 \%)$ \\
$35-39$ & $6(6 \%)$ \\
$40-44$ & $34(34 \%)$ \\
$45-49$ & $29(29 \%)$ \\
$50-54$ & $16(16 \%)$ \\
$55-59$ & $0(0 \%)$ \\
over 60 & $0(0 \%)$ \\
\hline
\end{tabular}

\subsection{Education and Work Experience}

For education attainment, around two fifth (39 per cent) construction workers were having primary school level, around half (51 per cent) subjects were having secondary 
school certificate level, one tenth (10 per cent) subjects were having postsecondary school diploma level (Table-2).

Table 2. Education attainment distribution.

\begin{tabular}{ll}
\hline Education attainment & Number (\%) \\
\hline Primary School & $39(39 \%)$ \\
Secondary School Certificate & $51(51 \%)$ \\
Postsecondary Diploma & $10(10 \%)$ \\
Bachelor Degree or above & $0(0 \%)$ \\
\hline
\end{tabular}

For working experience in construction industry, more than half were experienced workers, with 59 per cent worked more than 6 years (Table-3).

Table 3. Distribution of working experience in construction industry.

\begin{tabular}{ll}
\hline Working Experience & Number (\%) \\
\hline Less than 2 years & $11(11 \%)$ \\
2 years to 4 years & $13(13 \%)$ \\
4 years to 6 years & $17(17 \%)$ \\
6 years to 8 years & $36(36 \%)$ \\
More than 8 years & $23(23 \%)$ \\
\hline
\end{tabular}

\subsection{Working Conditions}

The average working hour per week of subjects was 54 hours (S.D. 6.63). Around half (48 per cent) subjects worked between $51-60$ hours and 20 per cent worked between $61-$ 70 hours (Table-4).

Table 4. Age distribution.

\begin{tabular}{ll}
\hline Working hour per week & Number (\%) \\
\hline$<30$ & $0(0 \%)$ \\
$31-40$ & $0(0 \%)$ \\
$41-50$ & $32(32 \%)$ \\
$51-60$ & $48(48 \%)$ \\
$61-70$ & $20(20 \%)$ \\
$71-80$ & $0(0 \%)$ \\
$>80$ & $0(0 \%)$ \\
\hline
\end{tabular}

\subsection{Personal or Private Activities}

Concerning the personal or private activity, on average a subject spent around 2.87 hours per day. Around one third (29 per cent) subjects spent less than 2 hours per day (Table5). More than half (54 per cent) spent more than 3 hours per day.

Table 5. Distribution of hours of personal or private activities per day.

\begin{tabular}{ll}
\hline Hours of personal or private activities per day & Number $(\%)$ \\
\hline$<2$ & $29(29 \%)$ \\
$>2-3$ & $17(17 \%)$ \\
$>3-4$ & $26(26 \%)$ \\
$>4-5$ & $12(12 \%)$ \\
$>5$ & $16(16 \%)$ \\
\hline
\end{tabular}

\subsection{Self-Perceived Work-Life Balance}

On average the degree of achieved work-life balance for subjects was $5.86(\mathrm{SD}=1.54)$ out of 10 . For achieved work-life balance no subject was $1-2$ out of 10 ; more than half workers (58 per cent) subjects achieved work-life balance $5-6$ of 10 ; a significant group of workers (14 per cent) achieved work-life balance $9-10$ out of 10 (Table-6).

Table 6. Distribution of degree of achieved work-life balance.

\begin{tabular}{ll}
\hline Degree of achieved work-life balance & Number (\%) \\
\hline 0 & $0(0 \%)$ \\
$1-2$ & $0(0 \%)$ \\
$3-4$ & $17(17 \%)$ \\
$5-6$ & $58(58 \%)$ \\
$7-8$ & $21(21 \%)$ \\
$9-10$ & $14(3 \%)$ \\
\hline
\end{tabular}

\subsection{Problems Due to a Disturbed Work-Life Balance}

25 per cent of the subjects reported prolonged fatigue level, sleepiness and extreme tiredness; 29 per cent reported did not have any private time for recreation activities or sports at all; 30 per cent reported did not have time staying with their partners and/or family (Table-7).

Table 7. Distribution of problems due to a disturbed work-life balance.

\begin{tabular}{ll}
\hline Type of problems: & Number (\%) \\
\hline $\begin{array}{l}\text { Productivity and/or work quality has reduced } \\
\text { dramatically due to long working hours. }\end{array}$ & $18(18 \%)$ \\
$\begin{array}{l}\text { Prolonged fatigue level, sleepiness and/or extreme } \\
\text { tiredness. }\end{array}$ & $25(25 \%)$ \\
$\begin{array}{l}\text { I get physically sick easily and/or frequently due to heavy } \\
\text { workload. }\end{array}$ & $4(4 \%)$ \\
$\begin{array}{l}\text { I do not have any private time for recreation activities or } \\
\text { sports at all. }\end{array}$ & $29(29 \%)$ \\
$\begin{array}{l}\text { My work has adversely affected my relationship with my } \\
\text { friends. }\end{array}$ & $13(13 \%)$ \\
$\begin{array}{l}\text { I don't have time staying with my partner and/or family. } \\
\text { I feel stressed out, depressed and/or exhausted after work. }\end{array}$ & $30(30 \%)$ \\
$\begin{array}{l}\text { Work pressure creates insomnia and/or poor diet } \\
\text { I become accident-prone }\end{array}$ & $4(4 \%)$ \\
$\begin{array}{l}\text { I do not want to get married } \\
\text { I do not want to have children }\end{array}$ & $3(3 \%)$ \\
\hline
\end{tabular}

\subsection{Mental Health Conditions}

The mean GHQ score was $9.66(\mathrm{SD}=4.31)$. Around one third subjects lied within the range $19-24$. Around one fourth subjects ( 25 per cent, 24 per cent) lied within the ranges $13-18$ and $25-30$ respectively (Table-8).

Table 8. Distribution of mental health conditions.

\begin{tabular}{ll}
\hline Summation of scores & Number $(\%)$ \\
\hline $0-6$ & $24(24 \%)$ \\
$7-12$ & $50(50 \%)$ \\
$13-18$ & $26(26 \%)$ \\
$19-24$ & $0(0 \%)$ \\
$25-30$ & $0(0 \%)$ \\
$31-36$ & $0(0 \%)$ \\
\hline
\end{tabular}

\subsection{Associations Among Working Hour, Work-Life Balance and Mental Health Condition}

To test for the association between working hours and work life balance, whether the duration of working hours was inversely related to work-life balance, the response of item 1 (number of hours a week actually work on average) were correlated with the response of item 3 (how much have achieved in terms of an ideal work-life balance, using 0-10, 0 
represents the worst case possible, 10 represents already ideal, and 5 being half-half) using correlation analysis. The Spearman $r$ was -0.48 . A negative value of $r$ showed an inverse relationship. Statistic test showed that $r$ was significantly different than zero $(\mathrm{P}<0.0001)$. A plotting of the duration of working hours against their work-life balance was shown on (Figure 1). Some linear relationship between the duration of working hours and the work-life balance could be found. The plots scattered quite widely.

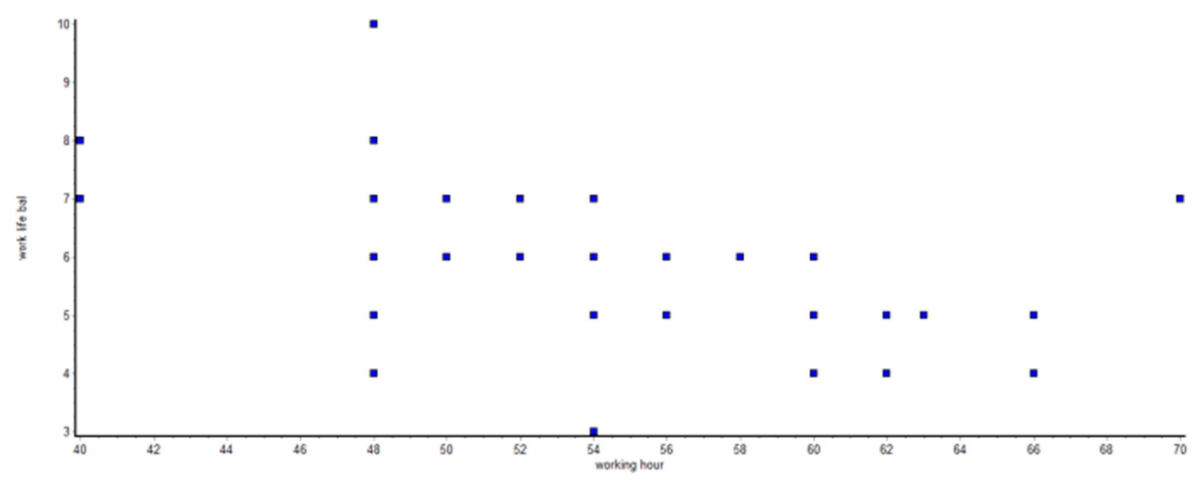

Figure 1. Plotting of the working hour against work-life balance.

To test for the association between working hours and mental health condition, the duration of working hours was inversely related to mental health condition, the response of item 1 were correlated with the GHQ score of item 5 using correlation analysis. The Spearman $\mathrm{r}$ was 0.58 . A positive value of $r$ showed an inverse relationship. Statistic test showed that $r$ was different than zero $(\mathrm{P}<0.0001)$. A plotting of the working hour against GHQ score was shown on (Figure 2). Some linear relationship between the working hours and the mental health condition could be found.

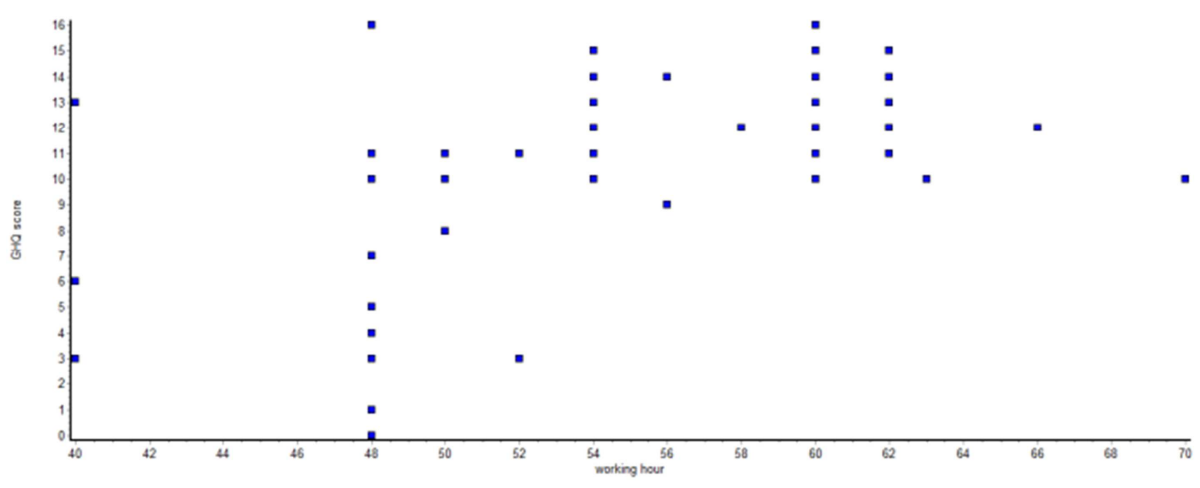

Figure 2. Plotting of the working hour against GHQ score.

To test for the association between work-life balance and mental health condition, the work-life balance was related to mental health condition, the response of item 3 were correlated with the GHQ score of item 5 using correlation analysis. The Spearman $r$ was -0.52 . A negative value of $r$ showed an inverse relationship. Statistic test showed that $r$ was significantly different than zero $(\mathrm{P}<0.0001)$. A plotting of the work-life balance against their GHQ score was shown on (Figure 3). Some linear relationship between the work-life balance and the GHQ score could be found. The plots scattered quite widely.

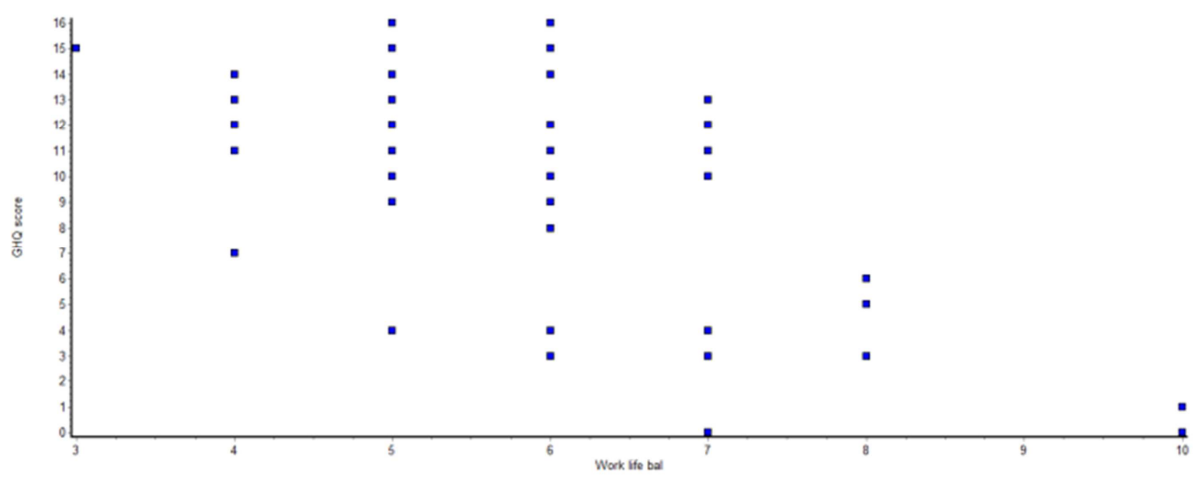

Figure 3. Plotting of the work-life balance against GHQ score. 


\section{Discussion}

The construction workers of Hong Kong have high rate of workplace accidents. This is the first study to investigate whether it was related to long working hour, poor work-life balance and poor mental health. The result showed the average work hour per week of construction workers in Hong Kong was around 54 hours with around half worked between 51 to 60 hours and with one fifth worked between 61 to 70 hours. This was significantly longer than other places with standard working hour legislation where the working hour per week was only 40 [7]. For other professions in Hong Kong [7], the average work hour per week was 48.4 hours. Therefore, construction workers had a longer working hour than other professions in Hong Kong and much longer working hour than other places with standard working hour legislation. However, they were not having the longest working hours, as a similar work-life balance study in Hong Kong working on another profession with long working hours, public doctors showed that the average work hour per week of public doctors was 57 hours [17]. This study also showed some unique characteristics of these workers: most of them were male (96 per cent); in general belonged to the middle age group; with a significant portion (40 per cent) having lower education attainment (primary school) but long working experience (around 60 per cent and more than 6 years) and mainly engaged in physical activities.

The work-life balance of construction workers was slightly better than that of other professions in Hong Kong. Concerning the personal or private activity, on average a construction worker spent around 2.87 hours per day. On average, the other professions spent 1.6 hours per day on their personal activities [7]. It showed that construction workers spent a little bit more time on their personal activities than other professions in Hong Kong. The result also showed the self-perceived work-life balance of construction workers was 5.86 out of 10 . This work-life balance condition was slightly better than the other professions, which was 5.7 out of 10 [7]. For the problems due to a disturbed work-life balance, one fourth ( 25 per cent) of the construction workers reported a disturbed work-life balance prolonged fatigue level, sleepiness and extreme tiredness. This percentage was much lower than another long working hour industries, public doctor (62 per cent). This showed while some construction workers were adversely affected by the disturbed work-life balance, the percentage was not as high as that of public doctors in Hong Kong. Therefore although the construction workers had long working hours, the results did not show the work-life balance of construction workers was poorer than that of other professions in Hong Kong.

This is also the first study to investigate the condition of mental health of construction workers in Hong Kong. The data can be used as a reference to compare with different professions, different working hours, different areas, different populations and different time periods. This can be highly useful especially in the field of working hours and work-life balance research. The mean GHQ score of the construction workers was 9.66. As there was no similar study on construction workers the result cannot be directly compared. However if we compare this with other population studies, like the mean GHQ score of Spanish general population (1001 aged 25-65) which was 8.52 ( $\mathrm{SD}=5.38)$ [15], it showed the mental health condition of the Hong Kong construction workers was only slightly poorer than those of the Spanish general populations. It was not possible to show the mental health condition of the Hong Kong construction workers as poor from the results.

To summarize the above, the working hour of construction workers was worse than many other professions in Hong Kong and other places. However, there was insufficient evidence to show their work-life balance and mental health were as poor as other long working hour industries in Hong Kong and to show their mental health condition was poor. Therefore, it was also not possible to relate the high risk of accidental injuries to the poor worklife balance and poor mental health. This might be related to the unique characteristics of construction workers mentioned above, namely mostly male, middle age, lower education attainment, long working experience and mainly engaged in physical activities. Further studies are needed to investigate whether these characteristics are contributing the better work-life balance and mental health in construction workers.

This is also the first study to work on the correlations among working hours, work-life balance and mental health on construction workers in Hong Kong. There existed some associations among working hours, work-life balance and mental health on construction workers in Hong Kong. Long working hours were associated with poor work-life balance and poor mental health condition. These associations were not strong because the plots scattered quite widely, possibly due to many variations within the populations and existence of many confounding factors. In addition, this study only showed the association, it did not prove the cause and effect relationship among different parameters. The latter, obviously, involved a multitude of factors and required longitudinal studies to verify.

\section{Conclusion}

In an area without standard working hour legislation, the working hours of Hong Kong construction workers was worse than many other professions in Hong Kong and in other places. There existed some associations among working hours, work-life balance and mental health. There was insufficient evidence to show their work-life balance and mental health were as poor as those of other long working hour industries in Hong Kong. There was insufficient evidence to show the high risk of occupational injuries was related to poor work-life balance and mental health. 


\section{References}

[1] Lowery, J., Borgerding, J., Zhen, B., Glazner, J. E., Bondy, J. and Kreiss, K. (1998) Risk factors for injury among construction workers at Denver International Airport. American Journal of Industrial Medicine, 34, 113-120.

[2] Dembe, A. E., Erickson, J. B., Delbos, R. G. \& Banks, S. M. (2005). The impact of overtime and long work hours on occupational injuries and illnesses: new evidence from the United States. Occupational and Environmental Medicine, 62, 588-597.

[3] Welford, R. (2008). Work-life balance in Hong Kong: Survey Result. The University of Hong Kong, Hong Kong. http://www.ethicsworld.org/ethicsandemployees/PDF\%20link s/Hong\%20Kong\%20WLB.pdf.

[4] Community Business. (2010). Definition of Work-life Balance.

http://www.communitybusiness.org/focus_areas/WLB.htm\#1.

[5] Virtanen, M., Ferrie, J. E., Singh-Manoux, A., Shipley, M. J., Stansfeld, S. A., Marmot, M. G. \& Kivimäki, M. (2011). Long working hours and symptoms of anxiety and depression: A 5year follow-up of the Whitehall II study. Psychological Medicine, 41 (12), 2485-2494.

[6] Frijters, P., Johnston, D. W. \& Xin, M. (2009). The mental health cost of long working hours: the case of rural Chinese migrants. Queensland: University of Queensland. http://www.iza.org/conference_files/LabEco2009/frijters_p93 1.pdf.

[7] Labour Department. (2012). Report of the Policy Study in Standard Working Hours. Government Logistics Department, Hong Kong.

[8] Chung, T. Y. R., Pang, K. L. K. \& Tong, Y. W. J. (2009). Work Life Balance Survey of the Hong Kong Working Population
2009. Hong Kong: The University of Hong Kong. http://www.communitybusiness.org/images/cb/publications/20 09/WLB09_HKU.pdf.

[9] Legislative Council, HKSAR. (2015) Panel on Manpower meeting on 17 March 2015. LC Paper No. CB(2)1258/14-15.

[10] Legislative Council, HKSAR. (2014) Labour supply in the construction industry. Press releases: May 7, 2014. http://www.info.gov.hk/gia/general/201405/07/P20140507048 3 _print.htm.

[11] Spurgeon, A., Harrington, J. \& Cooper, C. (1997). Health and safety problems associated with long working hours: a review of the current position, Occupational and Environmental Medicine, 6 (54), 367-375.

[12] Hospital Authority. (2010). Hospital Authority Mental Health Service Plan For Adults 2010-2015. Hong Kong: Hospital Authority.

[13] Goldberg, D. \& Williams, P. (1988). A user's guide to the General Health Questionnaire. Windsor: NFER-Nelson.

[14] Goldberg, D., Gater, R., Sartorius, N., Ustun, T., Piccinelli, M., Gureje, O. \& Rutter, M. (1997). The validity of two version of the GHQ in the WHO study of mental illness in general health care. Psychology Medicine, 27, 191-197.

[15] Sánchez-López, M. \& Dresch, V. (2008). The 12-Item General Health Questionnaire (GHQ-12): Reliability, external validity and factor structure in the Spanish population. Psicothema, 4 (20), 839-843.

[16] Zaheer, A., Islam, J. U. \& Darakhshan, N. (2015). Occupational Stress and Work-Life Balance: A Study of Female Faculties of Central Universities in Delhi, India. Journal of Human Resource Management, 4 (1), 1-5.

[17] Young, Y. F. F. (2013). The Work-Life Balance of Public Hospital Doctors in a Metropolitan City. International Journal of Business and Social Science, 4, 72-77. 